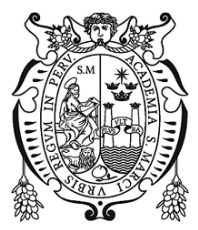

Revista de Investigación de Física 24(1), (Ene-Jun 2021)

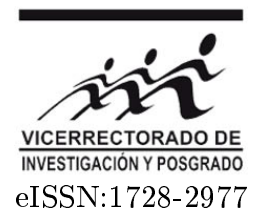

\title{
How physics-based techniques are helping to fight SARS-CoV-2
}

\author{
J. C. González*1,2 \\ ${ }^{1}$ Instituto de Ciencia de Materiales de Sevilla - CSIC, Grupo de Investigación de Superficies, Intercaras y \\ Láminas Delgadas. Sevilla 41092 - España \\ ${ }^{2}$ Universidad de Ingeniería y Tecnología (UTEC), Laboratorio de Física de Materiales e Ingeniería de \\ Superficies. Barranco 15063, Perú
}

Recibido 15 noviembre 2020 - Aceptado 14 diciembre 2020

\begin{abstract}
The new coronavirus called severe acute respiratory syndrome coronavirus 2 (SARS-CoV-2) causes an illness named coronavirus disease 2019 (COVID-19). Physicists along with other scientifics are all together in a counterclock race in order to defeat this novel virus. Physics-based techniques and methods are complementing the results coming from other disciplines such as chemistry, medicine, engineering and biotechnology. Let's take a look to know what physics-based techniques and methods can do to help to fight SARS-CoV-2.
\end{abstract}

Keywords: Coronavirus, SARS-CoV-2, COVID-19, physics techniques, physics method.

\section{Cómo las técnicas basadas en la física están ayudando a combatir el SARS-CoV-2}

\begin{abstract}
Resumen
El nuevo coronavirus llamado síndrome respiratorio agudo severo coronavirus 2 (SARS-CoV-2) causa una afección denominada enfermedad de coronavirus de 2019 (COVID-19). Los físicos junto con otros científicos están todos juntos en una carrera contrarreloj para derrotar a este nuevo virus. Las técnicas y los métodos basados en la física complementan los resultados de otras disciplinas como la química, la medicina, la ingeniería y la biotecnología. Echamos un vistazo para saber qué pueden hacer las técnicas y los métodos basados en la física para ayudar a combatir el SARS-CoV-2.
\end{abstract}

Palabras clave: Coronavirus, SARS-CoV-2, COVID-19, técnicas físicas, métodos de la física.

Coronaviruses are a broad family of viruses that normally affect only animals. Although coronaviruses were first identified nearly 60 years ago, some of them have ability to be transmitted from animals to people [Per09]. They produce clinical pictures that range from the common cold to more serious diseases [She20].

The new coronavirus is called severe acute respiratory syndrome coronavirus 2 (SARS-CoV-2), one illness caused by this virus has been named coronavirus disease 2019 (COVID-19) [Who20a], with over 62,4 million known infections by November 2020 worldwide, and it has reached pandemic status. Health workers and governments are doing their part to fight SARS-CoV-2 in several parts of the world, while physicist along with other scientists are trying to understand this novel virus in order to develop vaccines and treatments [Laz20] to get healthy of population affected around the world. In this sense, the problem-solving mindset of a physicist is very useful in many research fields of human knowledge so physics is at the forefront of this battle playing an important role to defeat SARS-CoV-2 by using physicsbased techniques and method such as X-ray crystallography, Cryo-electron microscopy, Computed tomography scans, Flow physics, Physics modeling, and Physical virology. In this brief communication we take a look to know what physics-based techniques and methods can do to help to fight SARS-CoV-2, and ultimately defeat it.

*juanc.gonzalez@icmse.csic.es 

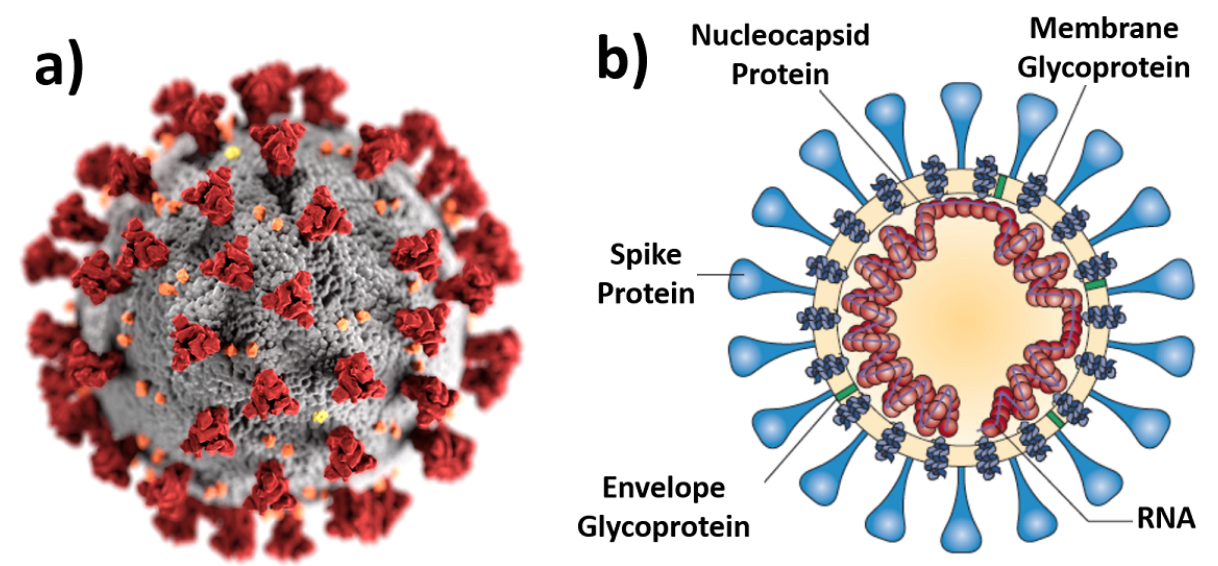

Figure 1: a) Ultrastructural morphology exhibited by coronaviruses. The spikes that adorn the outer surface impart the look of a corona surrounding the structural unit of the virus. Free distribution image obtained from reference [Eck20], and b) Schematic diagram of respiratory syndrome causing human coronavirus. Image adapted from reference [Per09].

\section{X-Ray Crystallography}

Crystallization of biological molecule results in the repetition of vast numbers of molecules in an ordered 3D lattice so they can diffract X-rays reinforcing all their tiny signals and become detectable by high sensitive detectors. These signals detected are not images of the molecules, because there are no materials that can substantially refract, and thereby focus, scattered X-rays. The signals detected are merely the sum of the contributions of X-rays diffracted from different parts of the molecule, then it is possible to obtain microstructural information of the molecule, through Fourier transform can split these contributions [Kne20] [Sha20]. Therefore, the calculated contributions are then equated with possible atomic structures by a lot of careful interpretation (mostly computer-driven) [Bio20].

\section{Cryo-Electron Microscopy}

Biological molecules can also diffract a electron beam. Cryo-electron microscopy is a technique applied to live samples cooled at very low temperatures. The molecules embedded in vitreous ice because an electron beam hit over the surface of biological sample heating up, and it is necessary do not destroy the sample with heat. Figure 1 shows ultrastructural morphology exhibited by coronaviruses [Eck20]. COVID-19 is a ribonucleic acid (RNA) virus, with a typical crown-like appearance under an electron microscope due to the presence of spikes on its envelope. The spikes are used to bind to host cells and thus enable the virus to make its way into the cells [Kle20]. The detailed structure of the spike protein is very useful for creating coronavirus vaccines. The body can build immunity if exposed to virus-like particles with the same external features while being hollow inside (without RNA) [Sch17].

\section{Computed Tomography Scans}

Computed Tomography imaging technology, known as a CT scan, employs a collimated beam of x-rays quickly rotated around of ill person in order to produce crosssectional images or slices of its body. Then, stacking all these cross-sectional images form a 3D image of the patient by using a mathematical algorithm. Medical physicists use the CT imaging technology provides very detailed information of soft tissues, blood vessels, and bones in various parts of the body. CT scans have become the first line of defence in the fight with coronavirus [Pon20]. It diagnoses suspected infections through searching of opaque spots within the lungs. The lungs are seriously compromised due to Covid-19 attacks which fail to function properly as a result of spreading of inflammation [Hos20] [Ma20].

\section{Flow Physics}

Flow physics plays a key role in nearly every feature of the COVID-19 global pandemic. This includes the generation and aerosolization of virus-laden respiratory droplets from a host, its airborne dispersion and deposition on surfaces [Bus20], as well as the subsequent inhalation of these bioaerosols by unsuspecting recipients. Moreover, fluid dynamics is key to preventative measures such as the use of face masks, hand washing, ventilation of indoor environments and even social distancing [Ver20]. Also, fluid dynamic analyses helped to understand the mechanisms behind how the droplets are generated in the respiratory tract, and also characterise the density, size and velocity of ejected droplets. Now, it is possible to estimate the settling distance, evaporation time, transport of the particles, and the effect of external factors such as air currents, temperature, and humidity by employing multiphase computational fluid dynamics in a fully coupled Euler-Lagrange framework [Dbo20]. 


\section{Physics Modeling}

Many researchers across the distinct disciplines have used diverse modeling tools to analyze the impact of this pandemic at global and local scales [Sin20] [Man20]. This includes a wide range of approaches, such as deterministic, data-driven, stochastic, agent-based, and their combinations, to forecast the progression of the epidemic in conjunction with the effects of non-pharmaceutical interventions to stop or mitigate its impact on the world population nevertheless these models need to capture the physical complexities of modern society [Who20b]. This includes the many ways of social contacts (for example social contact networks, transport systems, etc.) that may act as a framework for the virus propagation [Ari20]. But physics modeling not only plays a fundamental role in analyzing and forecasting epidemiological variables [Per20], but it also plays a key role in helping to find cures for the disease and in preventing contagion by means of new vaccines [Est20].

\section{Physical virology}

Viruses are highly ordered supramolecular complexes, and they are very diverse, spreading through cells of all kingdoms of life, they share common functions and properties [Roo10]. Their propagation is possible by kidnapping the host cell's machinery. Nowadays, there is a general interest in virology due to global pandemic, fundamental viral mechanisms are increasing importance in other areas such as biomedicine and (bio)nanotechnology [Sin06]. However, from a physical virology point of view is conceivable to optimally make use of viruses and virus-like particles, as vehicle for targeted drug delivery or as building blocks in electronics [Buz20], as well as to understand the selfassembly of viruses and the mechanical properties of viral particles [Sto10]. For that reason, it is essential to understand their key basic physical and chemical properties, and characteristics of viral systems.

From the viewpoint of a materials scientist, viruses can be considered as nanoparticles. Today, viruses are commonly employed in materials science as scaffolds for covalently linked surface modifications. The powerful physics-based techniques and methods are becoming the basis of nanomaterials engineering which can help defeat the global pandemic produced by this novel coronavirus. Finally, several laboratories around the world have generated immense knowledge about this novel virus that prepares us to defeat future pandemics.

\section{Acknowledgments}

Author thanks to CONCYTEC-FONDECYT (Peru) who financed this work under the contract number 2212015-FONDECYT, and Consejo Superior de Investigaciones Científicas (Spain) who also financed this work under the contract COOPB20349 (2018-2019).

\section{References}

[Ari20] Arias, F. (2020). Are Runners More Prone to Become Infected with COVID-19? An Approach from the Raindrop Collisional Model. Journal of Science in Sport and Exercise In press https://doi.org/ 10.1007/s42978-020-00071-4

[Bio20] Creative Biostructure (2020). X-ray crystallography platform for SARS-CoV-2, web: https : / www . creative-biostructure.com/ coronavirus/sars-cov-2-and-covid-19-p8.htm

[Bus20] Buzón, P., Maity, S., and Roos, W. (2020) Sneezing and asymptomatic virus transmission. Phys. Fluids 32, 073309 https://doi.org/10. $1063 / 5.0019090$

[Buz20] Buzón, P., Maity, S., and Roos, W. (2020) Physical virology: From virus self-assembly to particle mechanics WIREs Nanomed Nanobiotechnol. 12, (4) e1613 https://doi.org/10.1002/wnan.1613

[Dbo20] Dbouk, T., and Drikakis, D. (2020) On res- piratory droplets and face masks Phys. Fluids 32, 063303 https://doi.org/10.1063/5.0015044

[Eck20] Eckert, A., and Higgins, D. (2020) Highresolution image of Severe Acute Respiratory Syndrome coronavirus 2 (SARS-CoV-2). Public Health Image Library. CDC Organization. Web: https: //phil.cdc.gov/Details.aspx?pid=23312

[Est20] Estrada, E. (2020) COVID-19 and SARS-CoV2. Modeling the present, looking at the future. Physics Reports 869, 1 https://doi.org/10.1016/ j.physrep. 2020.07.005

[Hos20] Hossein1, H.,Ali, H., Hosseini, M., Sarveazad, A., Safari, S., and Yousefifard, M. (2020). Value of chest computed tomography scan in diagnosis of COVID-19; a systematic review and meta-analysis. Clinical and Translational Imaging In press https: //doi.org/10.1007/s40336-020-00387-9

[Kle20] Klein, S., Cortese, M., Winter, S., WachsmuthMelm, M., Neufeldt, C., Cerikan, B., Stanifer, M., Boulant, S., Bartenschlager, R., and Chlanda, P. (2020). SARS-CoV-2 structure and replication 
characterized by in situ cryo-electron tomography Nature Commun. 11, 5885. https://doi.org/10. 1038/s41467-020-19619-7

[Kne20] Kneller, D., Phillips, G., O’Neill, H., Jedrzejczak, R., Stols, L., Langan, P., Joachimiak, A., Coates, L., and Kovalevsky, A. (2020). Structural plasticity of SARS-CoV-2 3CL Mpro active site cavity revealed by room temperature X-ray crystallography. Nature Commun. 11, 3202. https://doi. org/10.1038/s41467-020-16954-7

[Laz20] Lazarus, J., Ratzan, S., Palayew, A., Gostin, L., Larson, H., Rabin, K., Kimball. S., and ElMohandes, A. (2020). A global survey of potential acceptance of a COVID-19 vaccine. Nature Medicine, 20 October 2020 https://doi.org/10. 1038/s41591-020-1124-9

[Ma20] Ma, H., and Zhang, Y. (2020). Computed tomography of covid-19 pneumonia. BMJ 370, 1807. http://dx.doi.org/10.1136/bmj.m1807

[Man20] Manrubia, S. (2020). The Uncertain Future in How a Virus Spreads. Physics 13, 166. https://physics.aps.org/articles/pdf/10. 1103/Physics .13.166

[Per09] Perlman, S., and Netland, J. (2009) Coronaviruses post-SARS: update on replication and pathogenesis. Nature Rev. Microbiology 7, 439 https://doi.org/10.1038/nrmicro2147

[Per20] Perc, M., Miksic, N., Slavinec, M., and Stožer, A. (2020) Forecasting COVID-19. Front. Phys. 8, 127 https://doi.org/10.3389/fphy . 2020.00127

[Pon20] Pontone, G., Scafuri, S., Mancini, M., Agalbato, C., Guglielmo, M., Baggiano, A., Muscogiuri, G., Fusini, L., Andreini, D., Mushtaq, S., Conte, E., Annoni, A., Formenti, A., Gennari, A., Guaricci, A., Rabbat, M., Pompilio, G., Pepi, M., and Rossi, A. (2020) Role of computed tomography in COVID-19. Journal of Cardiovascular Computed Tomography, In press https://doi.org/10.1016/j.jcct. 2020. 08.013

[Roo10] Roos, W., Bruinsma, R., and Wuite, G. (2010) Physical virology. Nature Phys. 6, 733 https:// doi.org/10.1038/nphys 1797
[Sch17] Schwarz, B., Uchida, M., and Douglas, T. (2017) Biomedical and Catalytic Opportunities of VirusLike Particles in Nanotechnology. Adv. Virus Res. 97, 1. https://doi.org/10.1016/bs.aivir.2016. 09.002

[Sin06] Singh, P., Gonzalez, M., and Manchester, M. (2006) Viruses and their uses in nanotechnology. Drug Development Research 67, 23. https://doi. org/10.1002/ddr. 20064

[Sha20] Shang, J., Ye, G., Shi, K., Wan, Y., Luo, C., Aihara, H., Geng, Q., Auerbach, A., and Li, F. (2020) Structural basis of receptor recognition by SARS-CoV-2. Nature 581, 221. https://doi.org/ $10.1038 / \mathrm{s} 41586-020-2179-\mathrm{y}$

[She20] Shereen, M., Khan, S., Kazmi, A., Bashir, N., and Siddique, R. (2020) COVID-19 infection: Origin, transmission, and characteristics of human coronaviruses. J. Adv. Res. 24, 91 https://doi. org/10.1016/j · jare.2020.03.005

[Sin20] Singer, H. (2020) The COVID-19 pandemic: growth patterns, power law scaling, and saturation. Phys. Biol. 17, 055001. https://doi.org/10.1088/ 1478-3975/ab9bf5

[Sto10] Stockley, P., and Twarock, R. (2010) The physics of virus assembly Phys. Biol. 7, 040301 https: //doi.org/10.1088/1478-3975/7/4/040301

[Ver20] Verma, S., Dhanak, M., and Frankenfield, J. (2020) Visualizing droplet dispersal for face shields and masks with exhalation valves. Phys. Fluids. 32, 091701. https://doi .org/10.1063/5.0022968

[Who20a] World Health Organization (2020) Naming the coronavirus disease (COVID-19) and the virus that causes it. World Health Organization https://www. who.int/emergencies/diseases/ novel-coronavirus-2019/technical-guidance/ naming-the-coronavirus-disease- (covid-2019) - and-the-virus-that-causes-it

[Who20b] World Health Organization (2020) Transmission of SARS-CoV-2: implications for infection prevention precautions. Scientific brief 9 July 2020. World Health Organization https://apps. who.int/iris/handle/10665/333114 